\title{
Las habilidades de pensamiento e informativas en el libro de texto de español: cronología de los planes de estudio en México
}

\section{Thinking Skills and Information Literacy in the Spanish Language Text Books: Chronology of study plans in Mexico}

\author{
Mariela González López* \\ Juan Daniel Machin Mastromatteo*** \\ Javier Tarango Ortiz ${ }^{* * * *}$
}

\begin{abstract}
*Doctoranda en Educación Artes y Humanidades de la Universidad Autónoma de Chihuahua (México). Maestra en Educación Básica por la Universidad Pedagógica Nacional del Estado de Chihuahua. Entre sus publicaciones recientes están: "Evaluación diagnóstica de habilidades de pensamiento e informativas para niños de primer grado de educación primaria" en Educare, 23(2), (2019); "Alfabetización Informacional: enseñanza y desarrollo de su competencia en la educación básica" en E-Ciencias de la Información, 9(2), (2019) y "La enseñanza de habilidades de pensamiento y de la comprensión lectora en estudiantes de bajo rendimiento escolar" en ARETÉ, (2019). Sus temas de interés son en educación. Correo electrónico: p324989@uach.mx
\end{abstract}

http://orcid.org/0000-0002-3178-8000

**Profesor en la Universidad Autónoma de Chihuahua (México). Es miembro del Sistema Nacional de Investigadores (SNI), Doctor en Ciencias de la Información y Comunicación (Tallinn University, Estonia), Master en Bibliotecas Digitales y Aprendizaje (Oslo and Akershus University College of Applied Sciences, Noruega; Tallinn University; y Parma University, Italia) y Licenciado en Bibliotecología (Universidad Central de Venezuela). Cuenta con 17 años de experiencia laboral en archivos, bibliotecas, educación superior y desarrollo profesional. Ha publicado más de 30 artículos científicos arbitrados e indizados, tres libros, 12 capítulos de libro y ha presentado ponencias en 44 conferencias internacionales. Correo electrónico: jmachin@uach.mx

http://orcid.org/0000-0003-4884-0474

***Profesor-Investigador de Tiempo Completo en la Universidad Autónoma de Chihuahua (México). Es miembro del Sistema Nacional de Investigadores (Nivel 2); Doctor en Educación por la Universidad Autónoma de Chihuahua, Maestro en Ciencias de la Información por la Universidad de Guanajuato y Maestro en Desarrollo Organizacional por la Universidad de Monterrey. Se encuentra adscrito a la Facultad de Filosofía y Letras, en los programas académicos de Maestría en Innovación Educativa y Doctorado en Educación, Artes $y$ humanidades (ambos reconocidos por el Programa Nacional de Posgrados de Calidad PNPC-CONACyT). Correo electrónico: jtarango@uach.mx

http://orcid.org/0000-0002-0416-3400

Historial editorial

Recibido: 02-febrero-2019

Aceptado: 14-julio-2019

Publicado: 23-septiembre-2019

ISSN-e: 2594-2956 


\section{Las habilidades de pensamiento e informativas en el libro de texto de español: cronología de los planes de estudio en México}

\section{Resumen}

Este artículo presenta un estudio histórico-lógico de los planes de estudio de educación primaria en México de 1973, I993, 20II y 20I7, a través de los libros de texto de español del primer grado, utilizados para el desarrollo y adquisición de la lectura y escritura en los niños. El objetivo es dar a conocer los modelos de lectoescritura y las habilidades de pensamiento e informativas que incluyen estos materiales, para realizar el análisis de convergencias y divergencias en cuanto a la calidad educativa. Las conclusiones, desde la perspectiva interpretativa y pedagógica, destacan que los métodos de enseñanza de la lectoescritura de 1973 a 2017 han sido el silábico, palabras normales, el método global o de análisis estructural y ecléctico. Hasta el momento se siguen implementando los mismos métodos, aunque las habilidades cognitivas se enseñaban más a menudo en los planes de estudios de 1973 a 1993. Además, las habilidades informativas son evidentes cuando se tratan de la selección de información y el abordaje de géneros documentales como periódicos, revistas, enciclopedias y libros de texto; aunque no son suficientes actividades para su desarrollo. En los planes de estudio de 201 y 2017 se promueve más el uso de herramientas digitales y el apoyo tecnológico.

Palabras Clave: Métodos de lectoescritura, libros de texto de español, planes de estudios de México, habilidades de pensamiento, habilidades informativas. 


\title{
Thinking Skills and Information Literacy in the Spanish Language Text Books: Chronology of study plans in Mexico
}

\begin{abstract}
This article focuses on a logical-historical research of elementary education study plans of the years 1973, I993, 20II and 2017 through first grade textbooks for Spanish Literacy Development used for children's reading and writing education. The purpose of the present study is to describe the underlying Spanish Literacy Development methods and approaches of these textbooks to provide an in-depth analysis of similarities and difference in terms of quality of content. The findings of this study, from an interpretative-pedagogical perspective, provide evidence to support the theory that Spanish Literacy Development methods from 1973 to 2017 in Mexico, have been: the syllable method, the sight word method, the global method, the analytic structural method, and the eclectic method. These methods are still used nowadays although cognitive skills strategies were used more frequently in the elementary school curriculum from 1973 to 1993 . The findings were also supportive of the theory that information seeking strategies for student's reading of newspapers, journals, encyclopedias and textbooks are infrequently used in Spanish Literacy Development syllabi, although in the study plans of 20II and 20I7, media literacy and digital competency are more frequently used.
\end{abstract}

Keywords: Literacy, Spanish literacy Development textbooks, Mexican study programs, cognitive skills, media literacy. 


\section{Pensée et information dans le manuel d'espagnol: chronologie des programmes au Mexique}

\section{Résumé:}

Cet article présente une étude historico-logique des programmes d'enseignement primaire de 1973, I993, 20II et 20I7, à travers les manuels d'espagnol de première année, utilisés pour le développement et l'acquisition de la lecture et de l'écriture par une partie des enfants. L'objectif est de faire connaître les modèles d'alphabétisation et les capacités de réflexion et d'information incluses dans ces ouvrages, afin de mener l'analyse des convergences et des divergences en termes de qualité de l'éducation. Les conclusions, du point de vue interprétatif et pédagogique, soulignent que les méthodes d'alphabétisation au Mexique de 1973 à 2017 ont été la syllabique, les mots normaux, la méthode globale ou l'analyse structurelle et éclectique. Jusqu'à présent, les mêmes méthodes sont toujours appliquées, même si les compétences cognitives ont été enseignées plus souvent dans les programmes de I973 à I993. De plus, les compétences informationnelles sont évidentes lorsqu'elles tentent de sélectionner des informations et de traiter des genres documentaires, tels que les journaux, les magazines, les encyclopédies et les manuels scolaires, mais pas assez d'activités pour son développement. Dans les programmes de $201 \mathrm{I}$ et 20I7, une plus grande utilisation des outils numériques et du support technologique est incluse.

22 Mots-clés: Capacité de raisonnement, Compétences informationnelles, Méthodes d'alphabétisation, Manuels d'espagnol, Programmes d'études mexicains. 
Umiejętność myślenia i zdobywania informacji na podstawie podręcznika z języka hiszpańskiego: kalendarium programu nauczania w Meksyku

\section{Streszczenie:}

W tym artykule przedstawiono historyczno-logiczne studium programów nauczania w szkole podstawowej z I973, I993, 20II i 20I7, za pośrednictwem podręczników z języka hiszpańskiego, wykorzystywanych do umiejętności nabywania czytania i pisania przez dzieci. Celem jest uwzględnienie modeli alfabetyzacji i umiejętności myślenia, które zawierają wymienione podręczniki, do przeprowadzenia analizy zbieżność i rozbieżności w zakresie jakości edukacyjnej. Wnioski opracowane zostaly $\mathrm{z}$ perspektywy interpretacyjnej i pedagogicznej, podkreślają, że metody nauczania alfabetyzacji w Meksyku od 1973 do 2017 wykorzystują ogólną metodę i analizę strukturalno-eklektyczna. Metody te są aktualnie używane, pomimo ze pochodzą z lat 1973 do I993. Ponadto, uzupelnione sa dodatkowymi zajęciami takimi jak: czytanie dokumentów na przykład gazet czy czasopism. Od lat 20II i 2017 programy nauczania obejmują szersze wykorzystanie narzędzi cyfrowych i wsparcie technologiczne.

Slowa kluczowe: metody czytanie i pisania, podręczniki z języka hiszpanskiego dla szkoly podstawowej, plany naucznia w Meksyku, zdolności myślenia i analizy. 


\section{Introducción}

Los libros de texto gratuitos para el alumno son una herramienta esencial para el aprendizaje porque promueven experiencias lectoras que llevarán al niño a desarrollarse en el mundo de la lectura y escritura, y serán la base para la construcción de saberes.

Este estudio implicó la revisión minuciosa de los planes de estudio de los años 1973, I993, 20II y 2017, especialmente sobre el contenido de los libros de español de primer grado editados por la Comisión Nacional de Libros de Texto Gratuitos (CONALITEG), que tiene el siguiente origen:

En febrero de 1959, el presidente Adolfo López Mateos aprobó la propuesta del secretario de educación Jaime Torres Bodet para que el Estado editara y distribuyera en forma gratuita libros de texto y cuadernos de ejercicios para todos los alumnos que cursaran educación elemental. Esta iniciativa surgía de la necesidad de cumplir con la gratuidad de la educación, estipulada por el artículo $3^{\circ}$ Constitucional. La obligatoriedad de los libros de texto gratuitos dio lugar a una enconada polémica. La diversidad de argumentos mostró el amplio frente organizado en contra de esta medida tomada por el gobierno. En buena parte el debate reflejó la antigua rivalidad entre el Estado y la Iglesia por el control del sistema educativo (Greaves, 200I, p. 205).

A 69 años de la llegada de los libros de texto gratuitos, el sistema educativo nacional sigue enfrentando como principales problemáticas la falta de comprensión lectora y bajo nivel de razonamiento verbal y matemático (Organización para la Cooperación y el Desarrollo Económicos [OCDE], 20I6). Además, la preparación relacionada con los 
métodos de lectoescritura sigue siendo un reto en estudiantes, formadores de maestros y docentes que imparten clases en primer grado de primaria. Estas dificultades -a nuestro juicio- pueden estar arraigadas en formas de enseñanza que no promueven competencias básicas, es decir, desarrollo de las habilidades del pensamiento (HP) y habilidades informativas (HI), indispensables para el razonamiento y el aprendizaje de la lectoescritura.

En México tradicionalmente se enseña la lectoescritura a los niños de entre cinco y seis años de edad, dada su madurez motora y física que los coloca en posibilidades para aprender a leer y escribir, aunque en las escuelas particulares comienzan con estas actividades en la etapa de preescolar. En ambos casos se busca el método que sea más adecuado y aceptado por el alumno, porque requiere del empleo de sus habilidades físicas, cognitivas, fisiológicas, emocionales y actitudinales. La escritura -además- requiere del control de los músculos y la motricidad del hombro, brazo y mano, junto con el desarrollo del proceso cognitivo y la concentración necesaria para realizar los trazos.

La lectura, por su parte, requiere del desarrollo de las HP: observar, comparar, clasificar, interpretar, percibir, describir y memorizar, que son sumamente importantes para el aprendizaje permanente y para pensar y resolver problemas (González-López, 2019); mientras que las HI se requieren tanto en lectura, como en escritura. Estas habilidades implican que el alumno aprenda a buscar, identificar, seleccionar y comunicar ideas, palabras y textos (González-López, MachinMastromatteo y Tarango, 2019). Para el desarrollo del lenguaje, el niño requiere de todas las habilidades anteriores.

La adquisición de la lectoescritura implica que el niño aprenda a escuchar y escribir, que entienda y aplique las reglas ortográficas, y que desarrolle procesos de atención y concentración. Se trata entonces de 
un proceso complejo que requiere tiempo, acompañamiento y materiales de apoyo -como el libro de texto- que ayuden al alumno a dominar dicho proceso. En el primer ciclo se necesita del aprendizaje del trazo gráfico, del apoyo sobre el lápiz y del deslizamiento de la mano alzada, apoyándose en el dedo meñique para ir del trazo continuo al discontinuo, de arriba hacia abajo, de la toma palmar a lo digital, del cierre circular al angular; además de animar al educando a leer, por medio de actividades independientes y lectura grupal (Salazar, 2008). El dominio de la lectura y la escritura es la base del aprendizaje permanente:

La lectura es el motor para el desarrollo y condición para la equidad, factor de identidad e inclusión social, el acceso al conocimiento y la información es un derecho de todo ciudadano. El mundo contemporáneo demanda un dominio más sofisticado de la lectura, la escritura y la cultura escrita. Formarse como usuario pleno de la cultura escrita tiene como condición necesaria estar alfabetizado [...] el Estado mexicano hace manifiesta su voluntad política para considerar al libro y la lectura como elementos estratégicos desde el punto de vista económico, social, cultural y educativo, indispensables para el desarrollo del país (Secretaría de Educación Pública [SEP], 2008, p. 6).

Una vez realizado el breve bosquejo de la importancia y condiciones de la lectoescritura, conviene resaltar que la relevancia de este trabajo 26 radica en que se analiza una parte del problema educativo, concerniente a dichos procesos, rastreando su origen en la falta de métodos para su enseñanza en los libros de texto, en los planes y programas de estudio y en las actividades dentro del salón de clases. Otro aspecto a considerar es la cantidad de actividades de HP y HI incluidas en los libros de texto, por lo que se estableció como objetivo 
determinar cuáles y cuántas se incluyen en estos materiales. Para ello se recurrió al análisis histórico lógico de siete etapas en los planes de estudio de 1973 a 2018.

La metodología aplicada fue: i) de nivel teórico-documental e histórico, ya que se establecieron relaciones pasado-presente; y ii) históricológico, pues se refiere a que existen relaciones de causa-efecto (Centty, 2006; Calzadilla-González, Mendoza-Cevallos y Diaz-Pompa, 2018). A través del análisis, se estudiaron los libros de texto de los planes de estudios de 1973 a 20I8, determinando si estos incluyen una cantidad razonable de $\mathrm{HP}$ y $\mathrm{HI}$, para su desarrollo. En los siguientes apartados presentamos la revisión de los libros de texto del primer grado, de las siete etapas históricas estudiadas.

\section{Primera etapa: libros de la generación 1972}

Para el plan de estudios de 1973, se analizaron los libros de español de primer grado, los cuales incluyen actividades para el desarrollo de la lectoescritura mediante el método alfabético, silábico y fonético. Adoptan un método integral y mixto para el desarrollo del lenguaje, la comunicación con otros y para la adquisición de habilidades de escucha, lectura y escritura (SEP, I972a, 1972b). De las HP, se observó que los libros tienen muchas actividades que promueven la observación, comparación, clasificación, interpretación, representación y descripción; por lo que se puede decir que son suficientes para que los alumnos aprendan a pensar. Además, en la década de 1970, el gobierno mexicano se esmeró por dar un nuevo impulso al desarrollo general del país, manteniendo un alto ritmo de crecimiento económico que propició bienestar entre la población (Instituto Nacional de Estadística y Geografía [INEGI], I970). 
Seguidamente, se observaron en este libro algunas actividades de identificación de información que implican el desarrollo de las HI. Las teorías de aprendizaje que prevalecen son la conductista y la asociacionista, aunque la cantidad de actividades para el desarrollo de las HI es muy deficiente.

Las decisiones tomadas en el plan de estudios de I973 influyeron en la reforma educativa desarrollada entre 1970 y 1976, que fue "el intento de reformular los procesos de subjetivación posteriores a la crisis de 1968 y de insertar los controles de la vida en los dispositivos estatales de seguridad" (González, 20I8, p. I). Mientras que en la década de 1970 comenzaban los planes de alfabetización a nivel mundial y se acuñaba el término de alfabetización informativa, en México el $4 \mathrm{I} \%$ de las personas mayores de seis años no sabían leer ni escribir, especialmente en localidades menores a 2,499 habitantes (INEGI, I970).

\section{Segunda etapa: libros de las generaciones 1982 y 1988}

Los libros de texto de las generaciones 1982 y 1988 tienen el mismo contenido, aunque muestran una fotografía diferente en las portadas, tanto en el correspondiente a las actividades como en los recortables. Estos materiales pertenecieron al plan de estudios 1973 e incluían prácticas de lectura en Mi libro de primero, Parte I (SEP, I980a) y Mi libro de primero, Parte 2 (SEP, I98ob). Sus complementos son: Mi libro

28 de primero, Recortable I (SEP, I980c) y Mi libro de primero, Recortable 2 (SEP, I980d).

El enfoque que plasman los libros es el mismo de la generación anterior: el método silábico como proceso de las marchas analíticassintéticas-analíticas; lo que refleja parte de la evolución que hubo en la 
enseñanza de la lectoescritura durante la segunda mitad del siglo XX, donde arribaron las propuestas globalizadoras que recogen lo más novedoso de los métodos existentes hasta entonces (Pérez, Hernández, y Trujillo, 2017 y 20I8). Por su parte, Olivera (2000) señala que fueron años de revolución educativa y descentralización frustrada de la educación básica y normal en la administración del presidente Miguel de la Madrid Hurtado.

El método silábico se adjudica a los pedagogos Federico Gedike y Samiel Heinicke hacia finales del siglo XVIII y consiste en el desarrollo de la lectoescritura a partir de la enseñanza de las vocales, posteriormente las consonantes, la formación de sílabas y después palabras (Limón, 20I6). El proceso enfatiza primeramente en conocer todo el abecedario, luego las vocales y sus sonidos, combinar las vocales con las consonantes, formar sílabas (diptongo, triptongo y complejas) y finalmente la combinación de silabas, formando nuevas palabras y oraciones.

Las HP que se proponen en estos libros son para desarrollar la observación, comparación, representación, memorización y descripción. Además, se incluyen actividades en diferentes materias (artística, civismo y ciencias sociales), estructuradas a base de preguntas. Aparecen actividades para que los niños se reconozcan, adquieran vocabulario y para que puedan expresarse. La división del texto se realiza en cuatro unidades, correspondientes a cada tema. Las actividades donde se desarrollan las HP son suficientes para aprender a pensar en esos días.

Por otra parte, las actividades para desarrollar las HI son limitadas y las que incluye son para identificación de elementos en dibujos. En el libro Recortable I (SEP, I980c) se observó que las propuestas incluidas son ejercicios de maduración: motricidad fina y gruesa, caligrafía, ejercicios 
para que el alumno tenga habilidad en la mano, entre otras relacionadas con el proceso de escritura. Los libros de la generación I988 solo cambian en el título y la portada.

\section{Tercera etapa: los libros de la generación 1993}

En 1992 inició el proceso de modernización educativa, que comprende los conceptos de eficiencia y calidad educativa. Por lo tanto, el plan de estudios de 1993 tuvo una propuesta didáctica estructural y comunicativa, mediante las teorías de aprendizaje constructivista, psicolingüística y sociolingüística. La primera implica que el alumno aprende y construye, mientras que la teoría psicolingüística busca la comunicación con otros para la comprensión, usando principios del lenguaje como objeto de construcción social, diverso y dinámico, considerando al sujeto activo, así como la adquisición y uso del conocimiento. La teoría sociolingüística se asocia con la dialectología, que implica el para qué sirve y para qué se usa el conocimiento.

Los libros de este plan de estudios plasmaron ejercicios para el desarrollo de la lectoescritura basados en el método de palabras normales, que puede describirse como analítico porque comienza desde palabra, pasa por la sílaba y llega a la letra. También es sintético porque va de la letra a la sílaba y de esta a la palabra. En un documento del Ministerio de Educación de Guatemala (MEG, 20I7), se precisan las

30 siguientes características del método:

[...] muestra una palabra que luego será analizada en sílabas y letras para finalizar con la recomposición de la palabra, mostrada al inicio, por medio de la síntesis [...] el método es de la siguiente manera: i) iniciar con un cuento breve o un juego 
para despertar el interés del estudiante; ii) presentar la palabra generadora que ya ha sido observada y escuchada en el cuento o durante el juego [...]; iii) analizar los elementos (cada grafema) que forman la palabra generadora por medio de la observación (el docente realiza la acción); [...] iv) posteriormente, el estudiante debe recomponer la palabra, es decir, identificar cada grafema y las sílabas que la componen para crear nuevas palabras con los sonidos [...]; v) a partir de la descomposición de la palabra en letras, se aprovecha para generar nuevas palabras al formar las sílabas que se pueden derivar de la letra en estudio; y vi) la lectura se desarrolla de forma simultánea a la escritura (pp. 26-27).

El libro integrado de primer grado (SEP, 1993a) posee contenidos estructurados en ocho temas: el autocuidado de los niños, la familia, lo que se puede hacer en la escuela, los derechos y deberes de los niños, la localidad, los seres vivos, el campo y la ciudad, el tiempo (pasado, presente y futuro) y las fechas conmemorativas de México. Incluye actividades para el desarrollo de las HP, donde el alumno debe observar, comparar, relacionar, describir, memorizar y crear; aunque no contempla ejercicios para la representación, interpretación e inferencias. Este libro puede considerarse suficiente para el desarrollo de las HP y para aprender a pensar.

En cuanto a las HI, solamente se incluyen contenidos sobre los medios de comunicación y difusión como la radio, el teléfono, la televisión y el periódico. El libro integrado de primer grado en modalidad de recortable (SEP, I993b) sólo complementa las actividades de su antecesor con nuevos recursos como los memoramas; mientras que el libro de español lecturas (SEP, I994) mostró un aumento considerable en actividades relacionadas con $\mathrm{HI}$. 
El plan de estudios de 1993 contempló los libros de actividades de español (SEP, I997a), español lecturas (SEP, I997b) y recortable (SEP, 1997c). El método plasmado en ellos fue el de palabras normales descrito con anterioridad, en tanto que en actividades se incorporó el enfoque silábico, que implicaba el uso de canciones, trabalenguas, poemas, cuentos, recortes y textos para el desarrollo de la lectoescritura. En el resto de los libros las actividades se encaminan hacia la adquisición de conocimientos, habilidades comunicativas y de lenguaje, tales como la escritura en letra script y en cursiva, la direccionalidad, el espacio entre palabras, identificación de mayúsculas en nombres propios y al inicio de párrafos, uso del punto final y punto y aparte, lectura en voz alta de textos de los alumnos y redacción.

En cuanto al desarrollo de HP, las actividades se relacionan con lectura de nombres, interpretación de ilustraciones, comparación de frases y objetos, y uso de palabras para descubrir la representación convencional de las letras. Se identifican HP para observar, comparar, recordar, crear, representar, describir y cuestionar; las cuales se consideran suficientes para el desarrollo de los alumnos y para aprender a pensar.

En cuanto a las HI se incluyen actividades de identificación y ubicación de palabras, uso del diccionario, localización de información y manejo de géneros documentales, por lo que podemos decir que las $\mathrm{HI}$ aumentaron, aunque no son suficientes para el desarrollo pleno de la competencia.

Cuarta etapa: los libros de la generación 2008 
En la reforma de 2009 (SEP, 2009a) se incorporaron las Tecnologías de la Información y Comunicación (TIC), y las bibliotecas escolares y de aula, donde los niños conocen diferentes géneros documentales. En conjunto, son elementos que pueden ejercer una mayor influencia sobre la formación de lectores y en el desarrollo de las HI.

La Reforma Integral de la Educación Básica (RIEB) -de 2009- mantiene el enfoque de las propuestas de 1993 y 2000 . Señala su identificación con las teorías de aprendizaje conductista (conducta) y asociacionista (semejanzas, contigüidad y causa-efecto) conjuntadas en una propuesta didáctica sociocultural, aplicada en la enseñanza de la lingüística estructural (SEP, 2009a). En el libro de español de primer grado (SEP, 2009b) se incorporan cinco bloques con dos proyectos que deben realizarse en un mes y medio, aproximadamente. En el último bloque del ciclo escolar aparece solo un proyecto y la autoevaluación.

Cada propuesta incluye título, ámbito al que pertenece, objetivo (el alumno escucha y habla) y materiales (escribe, lee y piensa, juega con las palabras, sabías qué, ahora busco, y reflexión y práctica). El libro de español recortable (SEP, 2009c) contiene recursos para construir historias, juegos de la lotería, dominó y memoramas. El método de lectoescritura utilizado es el global, que requiere del lenguaje oral, observación y motricidad. La convencionalidad de la escritura se enriquece gradualmente, a través de las siguientes etapas: i) preparatoria o de visualización; ii) formal de adquisición de los elementos de la lectura y escritura; y iii) de afirmación o consolidación del aprendizaje. El método global de análisis estructural se conjunta con el alfabético, silábico y fonético.

En el lenguaje oral se incluyen actividades para desarrollar la pronunciación y fluidez en la expresión, predicción de secuencias en el contenido de textos, comprensión y transmisión de órdenes e 
instrucciones, desarrollo de habilidades para expresar ideas y comentarios propios, conversación, lecturas y actividades con programas de radio y televisión, narración individual de experiencias o sucesos usando la habilidad de la descripción, entrevistas, discusión, comprensión de instrucciones y mímica, participación en juegos que requieran dar y comprender indicaciones, entre otras (SEP, 2009a).

Las HP que se observaron en el libro de español (SEP, 2009b) fueron: ordenar, observar, interpretar, recordar, comparar, emitir juicios, clasificar, crear cuentos y analizar información. Hubo aumento en cuanto a número, pero disminuyeron las actividades, por lo cual no se consideran suficientes para el desarrollo de la competencia. Respecto a las HI, se denotan en cada proyecto porque requieren que el alumno busque información y responda a cuestionamientos como: ¿sabes dónde puedes encontrar libros? u otras preguntas para usar el diccionario, ser un detective de libros, elegir un tema de investigación, dividir la información para compartirla a sus compañeros, comunicar noticias, llevar libros a casa para su lectura, revisar diferentes géneros documentales, identificar servicios en el periódico, entre otros temas. También se emplea la grabadora para elaborar un audiocuento, con lo cual podemos decir que aumentó la cantidad de actividades para el desarrollo de las HI, pero sin ser necesariamente suficientes.

\section{Quinta etapa: libros de la generación de $20 I I$}

El plan de estudios 2oII se apoyó en las teorías de aprendizaje del conductismo (conducta), constructivismo (construcción del conocimiento) y cognoscitivismo (aprende, procesa, da sentido y significado a lo que aprende) (SEP, 20II). La propuesta didáctica es mediante prácticas sociales de lenguaje, donde el estudiante produce 
textos y participa en eventos comunicativos. El libro de español de primer grado (SEP, 20I3) está estructurado de la misma forma que su homólogo para la generación de 2008, e incluye los mismos apartados para el desarrollo de los proyectos. Sin embargo, está organizado en cinco bloques, con tres proyectos hasta el cuarto bloque y dos para el último. De manera similar, el libro de español lecturas (SEP, 20I2) complementa el desarrollo de la lectoescritura a través del método ecléctico, cuyo proceso es el siguiente:

[...] se inicia con la introducción de los sonidos de las letras (método fonético) para que el estudiante identifique cada grafema por su fonema. Aunado, practican la creación de nuevas palabras (método de palabras normales) y la escritura por medio de dictados y la copia de letras, palabras y oraciones que desarrollan la comprensión de la forma de las letras. Con dichas actividades, logran relacionar lo oral y con lo impreso (Freeman y Serra, s/f, citado por MEG, 20I7, p. 30).

Las HP que buscan desarrollar con las actividades del primer libro (SEP, 20I3) son: observación, representación, comparación, clasificación, ordenación, descripción, percepción y memoria. Las HP que se plasman -relacionadas con el proceso de lectoescritura- son leer y distinguir de manera autónoma entre una variedad de géneros literarios (poesía, cuento y canciones), con diferentes objetivos: aprender, informarse o divertirse. Además, el alumno debe demostrar que comprende la lectura; las características generales de textos literarios, informativos y narrativos; las diferencias entre textos de fantasía y realidad; las preguntas para guiar la búsqueda de información y los procedimientos para comunicarla a otros. Dado que se ha mostrado un decremento de actividades de HP, se considera que estas no son suficientes. 
En los aspectos mencionados, podemos ver varios rasgos que corresponden a las HI, como son uso de fuentes de información para que los alumnos identifiquen palabras, analicen y disfruten de los textos. El proceso de lectura plantea preguntas para guiar la búsqueda de información y para que el alumno investigue, seleccione y organice la información de diversos temas para comunicarla a otros. También se busca que el alumno identifique las características de un libro y el tema (distinguir en qué se fijan los bibliotecarios para ordenar los materiales, saber qué libros hay en la biblioteca del aula y cómo puede organizarlos, predecir el tema que va a tratar un libro observando su cubierta).

Las HI que se reflejaron en las actividades concernientes al proceso de lectoescritura son: identificación de la información, los créditos iconográficos para centrar el lenguaje visual, bibliografía, escribir notas informativas, uso de géneros documentales como el periódico o el cuento, el fichero temático, recuperar información, seleccionar libros para la lectura, preguntas específicas (¿qué información hay? ¿para qué sirve?); además de consultas a bibliotecas digitales y organización de materiales en la de aula. Por lo tanto, dichas actividades han mostrado un incremento sustancial en el manejo de la competencia.

\section{Sexta etapa: libros de la generación de 2014}

36 Las teorías de aprendizaje empleadas en esta etapa fueron las mismas que en la generación de 20II: conductismo, constructivismo y cognoscitivismo. La propuesta didáctica se vincula a actividades sociales de lenguaje que corresponden al plan de estudios 20 II y que estuvieron vigentes hasta julio de 20I8. Los materiales son: libro de español para el alumno (SEP, 2OI4c), libro de español para el maestro 
(SEP, 20I4d), libro de lecturas (SEP, 20I4a) y libro de material de apoyo para la alfabetización (SEP, 20I4b). El texto de español del alumno está organizado en cinco bimestres con 20 lecciones cada uno.

El método de lectoescritura plasmado en el libro de español es el ecléctico, pero con mayor enfoque hacia la reflexión, socialización y razonamiento del alumno. Retoma actividades individuales, en equipo y grupales, empleando la técnica del juego. Las HP que se observan en las actividades para el proceso de la lectoescritura son: observar, ordenar palabras y tarjetas de palabras, comparar nombres o cosas, memorizar, representar un cuento por medio de un dibujo, clasificar, describir la acción de un personaje, emitir juicios, analizar el clima, crear poemas y analizar un cuento con base en preguntas. Por lo tanto, sí incluyen actividades para las HP, pero no son suficientes para su desarrollo.

Las HI que se reflejaron en las actividades para el proceso de la lectoescritura del libro de español son: localizar información, uso del diccionario para búsqueda de palabras y definiciones, recuperación de información y comunicación de datos proveniente de cuentos y artículos informativos.

Séptima etapa: libros de la generación del nuevo modelo educativo (2018-2019)

El plan de estudios 20I7, correspondiente al Nuevo Modelo Educativo para la educación obligatoria, comenzó a implementar en agosto de 20I8. Señala en su fundamentación que la sociedad y el Estado enfrentan la necesidad de construir un país más libre, que forme parte de un mundo interconectado, complejo y desafiante (SEP, 20I7). 
Enfatiza la necesidad de fomentar el hábito de lectura y la redacción de textos desde el primer grado de primaria, a través de una propuesta didáctica que contempla trabajo en equipo, inclusión, equidad y desarrollo socioemocional. Emplea las teorías de aprendizaje cognoscitivista y socioemocional.

El libro de español de primer grado (SEP, 20I8a) está organizado en tres bloques y todos los materiales de esta generación siguen empleando el método ecléctico, además del enfoque para la enseñanza de la lectoescritura con razonamiento analítico. Promueven el desarrollo de la memoria mediante la lectura, enfatizando el trabajo en equipo, la reflexión sobre el propio aprendizaje por medio de la coevaluación, la evaluación continua y el desarrollo de habilidades socioemocionales. El libro de español lecturas (SEP, 20I8b) ofrece material complementario para cubrir los mismos propósitos.

Las HP se reflejan en las secuencias para desarrollar la lectoescritura, como son: observar, recordar, memorizar trabalenguas, comparar, ordenar, describir animales, recordar lo aprendido y analizar por medio de preguntas. Las actividades son variadas, pero no son suficientes para el desarrollo de las HP. Las HI que se identifican para la lectoescritura son: localizar información por medio de preguntas, recuperar, representar, identificar títulos, investigar sobre animales en géneros documentales (revista, enciclopedias o videos), uso del diccionario, identificación de características de un libro, buscar información sobre un tema, seleccionar y comunicar lo aprendido.

\section{Conclusiones}


A lo largo de los años, el gobierno de México ha implementado varias reformas, acuerdos y planes de estudio tendientes a mejorar la calidad educativa en el país y de acuerdo a tal necesidad, se han realizado también modificaciones en los libros de texto. Los cambios han sido para incorporar herramientas que ayuden a la realización plena del individuo, generando con ello valor agregado a la sociedad y al propio Estado.

Este trabajo pone de manifiesto los diferentes enfoques para la enseñanza de la lectoescritura que han permeado en cada época, así como las teorías que los sustentan y sus contribuciones a las HP y HI que se reflejan en los planes de estudio y concretamente en los libros de texto. Se explicó la importancia de la lectoescritura en el primer grado de primaria, además de las contribuciones de las HP y HI para el desarrollo del proceso complejo en la lectoescritura.

En conclusión, el desarrollo del lenguaje oral y escrito corresponde a las actividades principales de la lectoescritura que están presentes en cada uno de los libros analizados. Debido a su enfoque lingüísticocompetencial, los estudiantes participan eficientemente en diferentes momentos de comunicación oral, además de conocer y valorar la diversidad lingüística y cultural de México.

De acuerdo al análisis desarrollado, puede considerarse que los objetivos principales del primer grado de primaria son que los niños lean y redacten comprensivamente diversos tipos de texto y que aprendan a pensar, para satisfacer sus necesidades de información y conocimiento. Igualmente, el estudiante reflexiona la escritura, específicamente sobre aspectos gráficos, ortográficos, de puntuación y morfosintácticos. 
En cuanto a los modelos de lectoescritura que se han practicado en la educación primaria, tenemos que los libros de texto de español utilizados en el plan de estudios de 1973 se rigieron bajo el método silábico, en el plan de 1993 se utilizó el de palabras normales, en 2008 se cambió al método global y desde el plan de estudios de $201 \mathrm{I}$ se emplea el método ecléctico. Los elementos mostrados ponen de manifiesto cierta evolución en los métodos de lectoescritura.

En general, para el proceso de enseñanza de la lectoescritura, todos los libros incluyeron varias actividades de HP y $\mathrm{HI}$, además de las habilidades de lenguaje oral, de expresión y escritura. Sin embargo, la cantidad de ejercicios de HP en los libros derivados de los planes de estudios 20II y 2017 no son suficientes para su desarrollo. Las HP son esenciales en el proceso de lectoescritura, por lo tanto, se demanda la implantación de nuevas estrategias y procesos de concientización a docentes, acerca de su enseñanza.

Las HP han sido elementos comunes en los planes de estudios de 1973 a 1993. Estas son importantes porque dan paso al aprendizaje de las letras, palabras y oraciones, donde el estudiante debe observar cada una de las grafías para realizar comparaciones entre unas y otras, lo cual lleva a representarlas por medio de símbolos para escribir textos y emplear la memoria para recordar la estructura silábica de las palabras y la clasificación para la organización de sílabas a palabras y oraciones. Sin embargo, no en todos los libros se ve reflejado algún método de enseñanza para que el maestro se ocupe de las HP.

\section{0}

De 1973 a 1993, los libros tenían pocas actividades para desarrollar las HI, como identificar palabras u oraciones. Sin embargo, a partir de 2008 fueron más evidentes, incrementándose en cada contenido, proyecto o bloque en que se divide el libro de español. Se han mejorado actividades como identificación de información en textos, 
comunicación, uso del diccionario y recomendaciones para la búsqueda de información en sitios web.

Las actividades de HI siguen siendo insuficientes, aunque constituyen una parte relevante durante el proceso de lectoescritura. La identificación de información en textos se debe incorporar a los libros. Los maestros deben realizar preguntas: $¿$ si les interesa más del tema, en donde lo buscarían? ¿Quién es el autor de la lectura? ¿Cuál es el año de esa lectura?

Los planes de estudio de 2011 y 2017 incluyeron un mayor número de actividades de HI para la lectoescritura y estrategias para la adquisición de conocimiento, haciendo uso de esquemas mentales sobre animales y con el juego de la lotería. Por parte de los maestros, el uso de las herramientas digitales facilita la enseñanza-aprendizaje de la lectoescritura.

Las actividades relacionadas con las HI que más se usaron para el proceso de la lectoescritura fueron: lectura icónica (iconografía para centrar el lenguaje visual), ubicación de palabras y uso de diccionarios, localización de información, diferenciación de géneros documentales, estrategias de búsqueda de información, identificación de elementos de calidad en la información, definición de temas de investigación, generación de contenidos, uso de las TIC, uso de bibliotecas tradicionales y digitales, y organización del conocimiento. Las temáticas vinculadas a las $\mathrm{HI}$, aunque no son suficientes, muestran precisión de contenidos y una presencia concreta en las estrategias educativas actuales.

A raíz de esta investigación, podemos proponer recomendaciones en relación a las políticas educativas en México, específicamente en cuanto a agregar la enseñanza de los diferentes métodos de lectoescritura en 
los planes de estudio de las escuelas normales y en las instituciones de educación superior de carácter privado que se dedican a la formación docente. Más allá de esto, se propone que los formadores de docentes obtengan conocimientos suficientes de los diferentes métodos de lectoescritura, especialmente sobre las tendencias modernas en cuanto a los procesos de alfabetización informativa, vinculada a los cambios radicales que experimenta la sociedad ante el exceso de fuentes de consulta y su respectiva conveniencia en su uso.

Para los libros de texto podemos recomendar que consideren de cinco a Io actividades (en cada bimestre o trimestre) para aprender a pensar durante el proceso de la lectoescritura: mapas mentales, HP (actividades para aprender a observar, comparar, clasificar, inferir, representar, describir, interpretar y analizar), HI (actividades para buscar información, seleccionar, analizar, evaluar, comunicar la información, identificar autor, año de publicación, tabla de contenido, títulos), uso de crucigramas, loterías, memoramas, trabalenguas, rompecabezas de cien piezas, adivinanzas (lectura y elaboración), sopas de letras (solucionen y elaboración) y videos con contenidos relevantes.

\section{Referencias}

Calzadilla-González, O.; Mendoza-Cevallos, A.; y Diaz-Pompa, F. (2018). Análisis histórico-lógico de la formación de los profesionales de la educación primaria en el contexto ecuatoriano. Journal for

42 Educators, Teachers and Trainers, 8(I), I57-I66.

Centty, D. (2006). Manual metodológico para el investigador científico. Arequipa, Perú: Universidad Nacional de San Agustín de Arequipa.

González-López, M. (2019). La enseñanza de habilidades de pensamiento y de la comprensión lectora en estudiantes de bajo 
rendimiento escolar. Areté. Revista Digital del Doctorado en Educación de la Universidad Central de Venezuela, 5(9), I45-I67. Recuperado de: http://saber.ucv.ve/ojs/index.php/rev_arete/article/view/I6284

González-López, M.; Machin-Mastromatteo, J.D.; y Tarango Ortiz, J. (2019). Alfabetización Informacional: Enseñanza y desarrollo de su competencia en la educación básica. E-Ciencias de la Información, 9(2), 3-I9. DOI: IO.I55I7/eci.v9i2.35774

González, R. (20I8). La reforma educativa en México: 1970-I976. Espacio, Tiempo y Educación, 5(I), 95-II8. DOI: IO.I45I6/ete.2I4.

Greaves Laine, C. (200I). Política educativa y libros de texto gratuito. Una polémica en torno al control por la educación. Revista Mexicana de Investigación Educativa, 6(I2), 205-22I. Recuperado de:

http://www.comie.org.mx/documentos/rmie/vo6/noI2/pdf/rmie vo6ni2scBo2noies.pdf

INEGI [Instituto Nacional de Estadística y Geografía]. (I970). IX Censo general de población de 1970. México: Instituto Nacional de Estadística y Geografía. Recuperado de: http://www.beta.inegi.org.mx/programas/ccpv/I97o/default.htm 1

Limón, R. (2016). Sistema de desempeño de la lectoescritura. Hermosillo, Sonora: Instituto del Desierto de Santa Ana. DOI: IO.I3I4O/RG.2.2.34427.31525

MEG [Ministerio de Educación de Guatemala]. (2017). Actividades exitosas en la enseñanza de le lectura en primer grado. Experiencias docentes, un estudio cualitativo. Guatemala: Dirección General de Evaluación e Investigación Educativa. Recuperado de: http://www.mineduc.gob.gt/digeduca/documents/investigacion es/20I8/ACTIVIDADES EXITOSAS.PDF

OCDE [Organización para la Cooperación y el Desarrollo Económico] (20I6). PISA 20I5. Resultados Clave. Recuperado de: https://www.oecd.org/pisa/pisa-20I5-results-in-focus-ESP.pdf 
Olivera, M. (2000). Evolución histórica de la educación básica a través de los proyectos nacionales: I92I-I999. Recuperado de: http://biblioweb.tic.unam.mx/diccionario/htm/articulos/sec 6.h $\underline{\mathrm{tm}}$

Pérez Piñón, F.A., Hernández Orozco, G.; y Trujillo Holguín, J.A. (2018). Narrativas: Cómo aprendimos a leer y escribir. RECIE. Revista Electrónica Científica de Investigación Educativa, 4(I), 47-54. Recuperado de: http://www.rediech.org/ojs/20I7/index.php/recie/article/view/29 3

Pérez Piñón, F.A.; Hernández Orozco, G.; y Trujillo Holguín, J.A. (20I7). Los métodos que hicieron divertido aprender a leer $y$ escribir en Chihuahua. Ponencia presentada en el Congreso Nacional de Investigación Educativa (COMIE), San Luis Potosí, México.

Salazar, R. (2008). Hacia mejores prácticas de lecto-escritura en el aula de primero y segundo grado de educación primaria (Tesis de licenciatura). Universidad Pedagógica Nacional, Ciudad de México.

SEP [Secretaría de Educación Pública]. (1972a). Español: Primer grado. México: Secretaría de Educación Pública.

SEP. (I972b). Español: Primer grado, recortable. México: Secretaría de Educación Pública.

SEP. (1980a). Mi libro de primero: Parte I. México: Secretaría de Educación Pública.

SEP. (1980b). Mi libro de primero: Parte 2. México: Secretaría de Educación Pública.

44 SEP. (I980c). Mi libro de primero: Recortable, parte I. México: Secretaría de Educación Pública.

SEP. (I980d). Mi libro de primero: Recortable, parte 2. México: Secretaría de Educación Pública.

SEP. (1993a). Libro integrado: Primer grado. México: Secretaría de Educación Pública. 
SEP. (I993b). Libro integrado: Primer grado, recortable. México: Secretaría de Educación Pública.

SEP. (1994). Español: Primer grado, lecturas. México: Secretaría de Educación Pública.

SEP. (1997a). Español: Primer grado, actividades. México: Secretaría de Educación Pública.

SEP. (1997b). Español: Primer grado, recortable. México: Secretaría de Educación Pública.

SEP. (1997c). Español: Lecturas. México: Secretaría de Educación Pública.

SEP. (2008). México Lee. Programa de fomento para el libro y la lectura.

México: Secretaría de Educación Pública. Recuperado de: https://sic.cultura.gob.mx/documentos/1219.pdf

SEP. (2009a). Planes y programas de estudio de 1993 y 2009: Reforma Integral de la Educación Básica. Puntos de continuidad y/o cambio. México: Secretaría de Educación Pública. Recuperado de: https://docentestlaxcala.files.wordpress.com/20II/08/comparati vo-sep-I993-2009-puntos-de-continuidad.pdf

SEP. (2009b). Español: Primer grado, recortable. México: Secretaría de Educación Pública.

SEP. (2009c). Español: Primer grado, lecturas. México: Secretaría de Educación Pública.

SEP. (20II). Plan de estudios 20II. Educación básica. México: Secretaría de Educación Pública. Recuperado de: https:/www.gob.mx/cms/uploads/attachment/file/20I77/Plan_d e Estudios 20II f.pdf

SEP. (2012). Español lecturas. México: Secretaría de Educación Pública.

SEP. (2013). Español: Primer grado. México: Secretaría de Educación Pública.

SEP. (20I4a). Español: Libro de lectura, primer grado. México: Secretaría de Educación Pública. 
SEP. (20I4b). Material de apoyo en la alfabetización inicial, tiras recortables y cartel con el alfabeto, primer grado. México: Secretaría de Educación Pública.

SEP. (20I4c). Español: Libro para el alumno, primer grado. México: Secretaría de Educación Pública.

SEP. (20I4d). Español: Libro para el maestro, primer grado. México: Secretaría de Educación Pública.

SEP. (20I7). Aprendizajes claves para la Educación Integral. Plan y programas de estudio para la educación básica. México: Secretaría de Educación Pública. Recuperado de: https://www.aprendizajesclave.sep.gob.mx/descargables/APRE NDIZAJES_CLAVE_PARA_LA_EDUCACION_INTEGRAL.pdf

SEP. (2018a). Lengua materna. Español. Primer grado. México: Secretaría de Educación Pública.

SEP. (20I8b). Lengua materna. Español lecturas. Primer grado. México: Secretaría de Educación Pública.

Este artículo se publica bajo una licencia de Creative Commons Reconocimiento-NoComercial 4.0 Internacional, y puede ser usados gratuitamente para fines no comerciales, dando los créditos a los autores y a la revista.

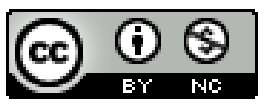

